\title{
Evaluating the Influence of Ageing Temperature on the Mechanical Properties of Al-Mg-Si Alloy
}

\section{I.O. Oladele and J.A. Omotoyinbo}

\author{
Metallurgical and Materials Engineering Department Federal \\ University of Technology, Akure. Ondo State, Nigeria.
}

\begin{abstract}
The effect of ageing temperature on the mechanical properties of Al-Mg-Si alloy has been studied. The material was machined into different shapes of the tests to be carried out: tensile, impact and hardness. The test specimens were divided into two and, some sets were solution treated at $500^{\circ} \mathrm{C}$ for one hour and peak aged at $160^{\circ} \mathrm{C}$ for eight hours while the other sets were solution treated at $500^{\circ} \mathrm{C}$ for one hour and peak aged at $180^{\circ} \mathrm{C}$ for eight hours. The abovementioned tests were carried out on the specimens. The results show that at low ageing temperature of $160^{\circ} \mathrm{C}$, the ductility and impact were high while at $180^{\circ} \mathrm{C}$, the ultimate tensile strength and hardness are higher compared to the value obtained at $160^{\circ} \mathrm{C}$.
\end{abstract}

Keyword: Ageing temperature, mechanical properties, solution treated, specimen.

\section{INTRODUCTION}

Aluminium does not have good casting or mechanical properties. These properties can be achieved by adding magnesium and silicon to aluminium. The addition of these alloying elements increases the aluminium response to heat treatment due to formation of $\mathrm{Mg}_{2} \mathrm{Si}$ intermetallic compound, which improves the casting, corrosion resistance property as well as the strength of the alloy. This alloy is named as the 6063 aluminium alloy. Al+Mg+Si alloy is also known as architectural and decorative alloy; because of its easy extrudability property, distinctly superior fnishing quality and strength. Almost half of all the aluminium extrusions produced in UK are used in building [1].

Structural medium strength aluminum alloys based on the Al-Mg-Si system have been popular for a wide range of applications for a long time. These alloys are widely used for decorative, architectural and structural applications. The development of Al-Mg-Si alloys for light structures has led to an increasing market for extrusions of intricate shape, medium strength and good toughness. These alloys are required to meet specific tensile properties and good fatigue strength, welding characteristics and formability [2]. Alloys based on the Al-Mg-Si-Cu system are widely 
used as medium strength alloys with major applications in extruded products and automotive body sheet.

AA6061 is one of the most widely used alloys from this group and optima mechanical properties are achieved by aging in the temperature range from $175^{\circ} \mathrm{C}$ to $180^{\circ} \mathrm{C}$ for 10 to 20 hours after solution treatment and quenching [3].

Heat treatment encompasses all operations of controlled heating and cooling of metals and their alloys in the solid state for the purpose of changing their structure and consequently their properties [4]. The common heat treatment operation for aluminum alloys is called ageing. This is the method of precipitating from solid solution a metastable phase that leads to change in properties of the alloy [5-6].

Nowadays, age hardened $\mathrm{Al}-\mathrm{Mg}-\mathrm{Si}$ alloys are widely used in construction and automotive industries. These alloys have been studied extensively for their exceptional increase in strength obtained by precipitation hardening. In order to control the precipitate distributions for these alloys, it is important to select proper silicon and magnesium contents, and also proper aging conditions [7]. This work was carried out to investigate the effect of ageing temperature on the mechanical properties of Al-Mg-Si alloy at the chosen temperatures.

\section{EXPERIMENTAL PROCEDURE}

Al-Mg-Si alloy with the following chemical composition as shown in Table 1 was used in this work.

Table 1. Chemical Composition of the Aluminum Alloy Sample (in wt \%).

\begin{tabular}{|l|l|l|l|l|l|l|l|l|l|l|}
\hline Elements & $\mathrm{Al}$ & $\mathrm{Mg}$ & $\mathrm{Si}$ & $\mathrm{Fe}$ & $\mathrm{Mn}$ & $\mathrm{Cu}$ & $\mathrm{Cr}$ & $\mathrm{Ti}$ & $\mathrm{Ca}$ & $\mathrm{Sr}$ \\
\hline Compositi & 98.663 & 0.432 & 0.362 & 0.046 & 0.151 & 0.003 & 0.002 & 0.006 & 0.01 & 0.015 \\
on & 1 & 1 & 5 & 9 & 6 & 6 & 6 & 2 & 1 & 6 \\
\hline
\end{tabular}

The material was machine into the shapes of the tests to be carried out on the lathe machine from where tensile and impact specimens were produced. Ten specimens were prepared for tensile test while six specimens were prepared for impact and hardness tests each. These specimens were subjected to two different heat treatment conditions. The first sets were subjected to solution treatment at $500^{\circ} \mathrm{C}$ for one hour, quenched in water and peak aged at $160^{\circ} \mathrm{C}$ for eight hours before finally quenched in water. The other sets were subjected to solution treatment at $500^{0} \mathrm{C}$ for one hour, quenched in water and peak aged at $180^{\circ} \mathrm{C}$ for eight hours before finally quenched in water. The following tests were carried out on the specimens.

\subsection{Tensile Test}

The specimen was clamped to the teeth of the tensiometer and load was gradually applied manually. The value of the applied load was indicated by the pointer in the mercury bulb. The effect of this load was also displayed on the graph sheet that was fixed at one end of the machine. The applied load stopped immediately the specimen breaks and the graph show the relation 
between the load and the extension produced. The percentage elongation was determined from the specimen with the use of vernier caliper.

\subsection{Impact Test}

The test was carried out by placing the specimen on the anvil of the pendulum of a charpy impact testing machine and the load was apply suddenly by the failing pendulum. As the pendulum swings past, it carries a pointer to its highest point of swing thus, indicating the amount of energy used in fracturing the test piece.

\subsection{Hardness Test}

The Rockwell hardness scale B testing machine with hardened steel ball as the indenter was used. A force was applied to press the indenter in contact with the surface followed by another force that causes an increase in depth of the indenter penetration into the material. The calibrated dial scale read the hardness value of the material obtained by counseling the minor load before applying the major load.

\subsection{Metallographic Analysis}

The prepared specimen surfaces were smoothened by grinding with the modern hand grinding deck using emery paper of progressive finer grades 220, 230, 400 and 600. They were polished with polishing machine using fine alumina as the polishing powder to obtain a mirror like surface. The polishing disk was covered by solvyt cloth and there was constant supply of water as lubricant. The sample were etched using freshly prepared dilute hydrofluoric acid $\left[50 \mathrm{~cm}^{3} \mathrm{NH}_{3}\right.$ $(\mathrm{OH})_{4}$ and $\left.50 \mathrm{~cm}^{3} \mathrm{H}_{2} \mathrm{O}\right]$ as enchants. The surfaces were observed under the microscope and their photograph's taken with magnification x 100 .

\section{RESULTS AND DISCUSSION}

\subsection{Influence of Ageing Temperature on the Ultimate Tensile Strength of Al- Mg-Si alloy.}

Ultimate tensile strength is the stress attained at the highest applied force before necking in ductile metals [8-9] like aluminium. Figures 1 (a) and (b) show that specimen aged at $160^{\circ} \mathrm{C}$ has $149.85 \mathrm{~N} / \mathrm{mm}^{2}$ UTS while specimen aged at $180^{\circ} \mathrm{C}$ has $189.70 \mathrm{~N} / \mathrm{mm}^{2}$.

Ductility and yield strength are some of the variables that are used to measure the UTS of a metal.

Ductility is the measure of the amount of deformation a material can withstand without breaking. This is determined by the percentage elongation values as shown in Figure 1(c). Specimen aged at $160^{\circ} \mathrm{C}$ has $16.75 \%$ elongation while specimen aged at $180^{\circ} \mathrm{C}$ has $16.54 \%$ elongation. 


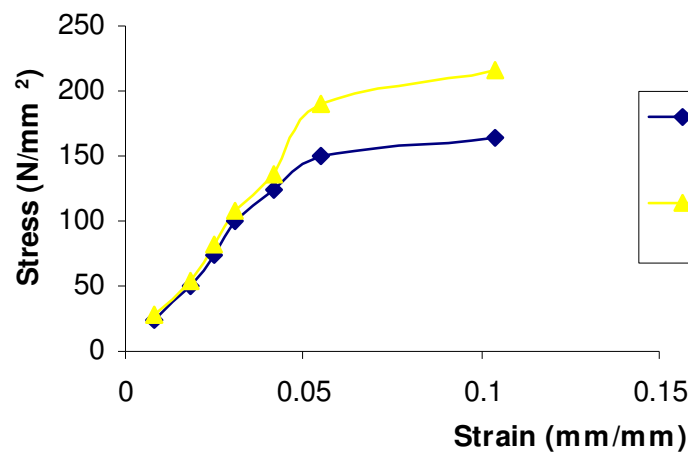

Figure1a:Stress-Strain Curve for Successively Hotworked and Aged Samples at $160^{\circ} \mathrm{C}$ and $180^{\circ} \mathrm{C}$.

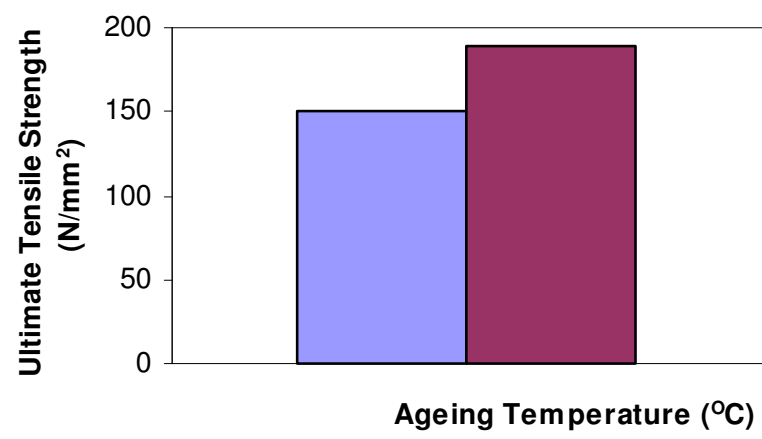

$\square$ UTS at 160

$\square$ UTS at 180

Figure1b:Variation of Ultimate Tensile Strength with Ageing Temperature at $160^{\circ} \mathrm{C}$ and $180^{\circ} \mathrm{C}$.

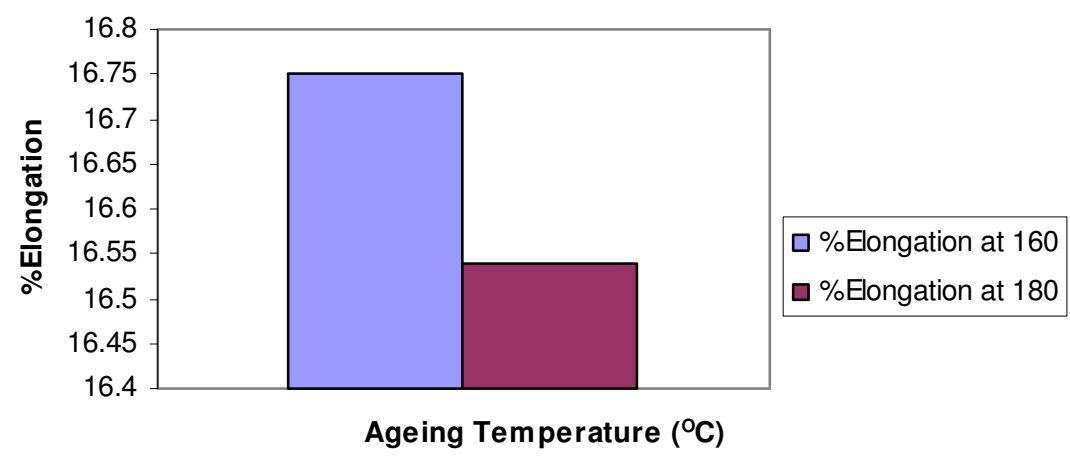

Figure1c: Variation of \%छlongation with Ageing Temperature at $160^{\circ} \mathrm{C}$ and $180^{\circ} \mathrm{C}$. 
Yield strength is the stress at which plastic deformation become noticeable. It is the stress required for dislocation to slip and it is the stress that divides the elastic and plastic behaviour of metal. In aluminium and its alloys, this stress is not easily detected and $0.2 \%$ proof stress is used to determine the offset of yield strength. It was determined from Figure 1 (d) that, the yield strength of specimen aged at $160^{\circ} \mathrm{C}$ is $124.87 \mathrm{~N} / \mathrm{mm}^{2}$ while specimen aged at $180^{\circ} \mathrm{C}$ has $189.70 \mathrm{~N} / \mathrm{mm}^{2}$. From the results; it was observed that specimen aged at $180^{\circ} \mathrm{C}$ has improved strength than specimen aged at $160^{\circ} \mathrm{C}$.

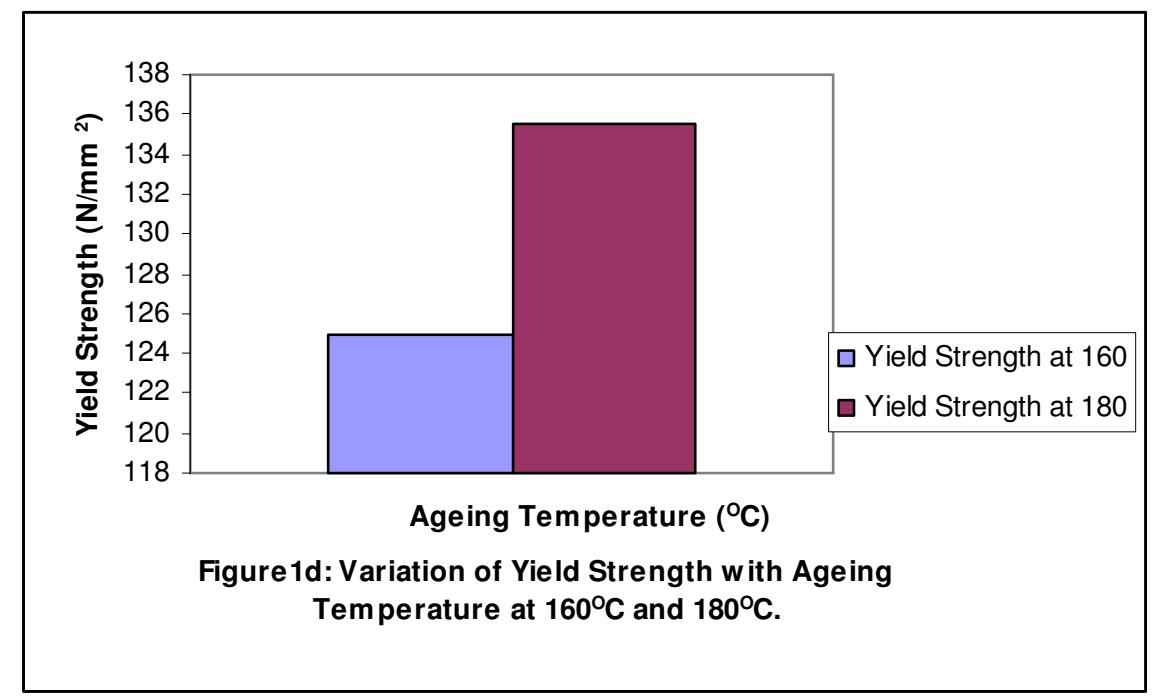

\subsection{Influence of Ageing Temperature on the Impact Energy of Al-Mg-Si alloy.}

Impact test is often used to evaluate the brittleness of a material under a sudden intense blow in which the strain rate is extremely rapid. Specimen aged at $160^{\circ} \mathrm{C}$ absorbed more energy (35.03J) before fracture than specimen aged at $180^{\circ} \mathrm{C}$ that absorbed (23.23J) as a result of high ductility experienced by specimen aged at $160^{\circ} \mathrm{C}$. This was shown in Figure 2 .

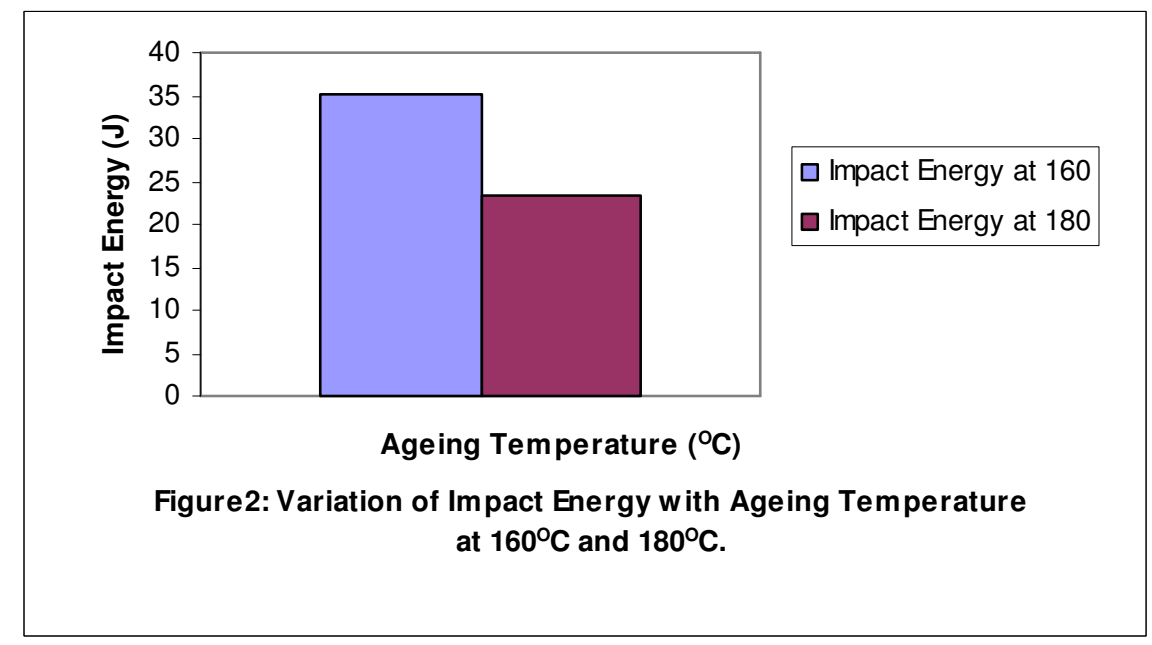




\subsection{Influence of Ageing Temperature on the Hardness of Al-Mg-Si alloy.}

Hardness test measure the resistance of the surface of a material to penetration or indentation. Figure 3 show the response of the specimens to hardness at $160^{\circ} \mathrm{C}$ and $180^{\circ} \mathrm{C}$. Specimen aged at $180^{\circ} \mathrm{C}$ has high hardness of 53HRB than specimen aged at $160^{\circ} \mathrm{C}$ that has $43 \mathrm{HRB}$ as a result of improved strength of the specimen.
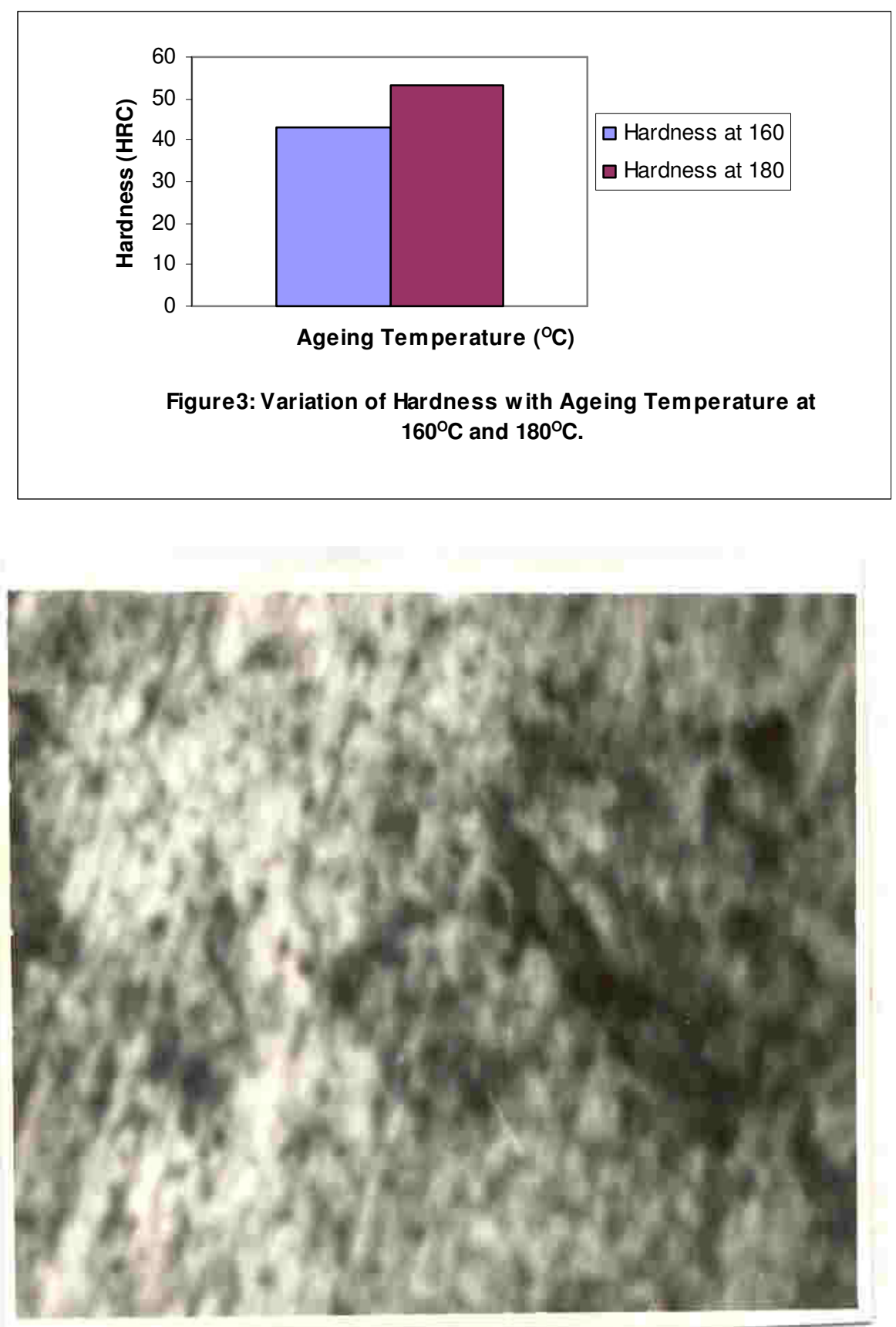

Figure 4. Microstructure of Sample Treated at $160{ }^{\circ} \mathrm{C}$. Magnifications (x100) 
The microstructure revealed the response of the aluminium alloy to heat treatment due to formation of $\mathrm{Mg}_{2} \mathrm{Si}$ intermetallic compound (black). The revealed structure in Figure 4 shows a clumsy precipitate of the $\mathrm{Mg}_{2} \mathrm{Si}$ intermetallic compound in Al-Matrix at the right side of the Figure.

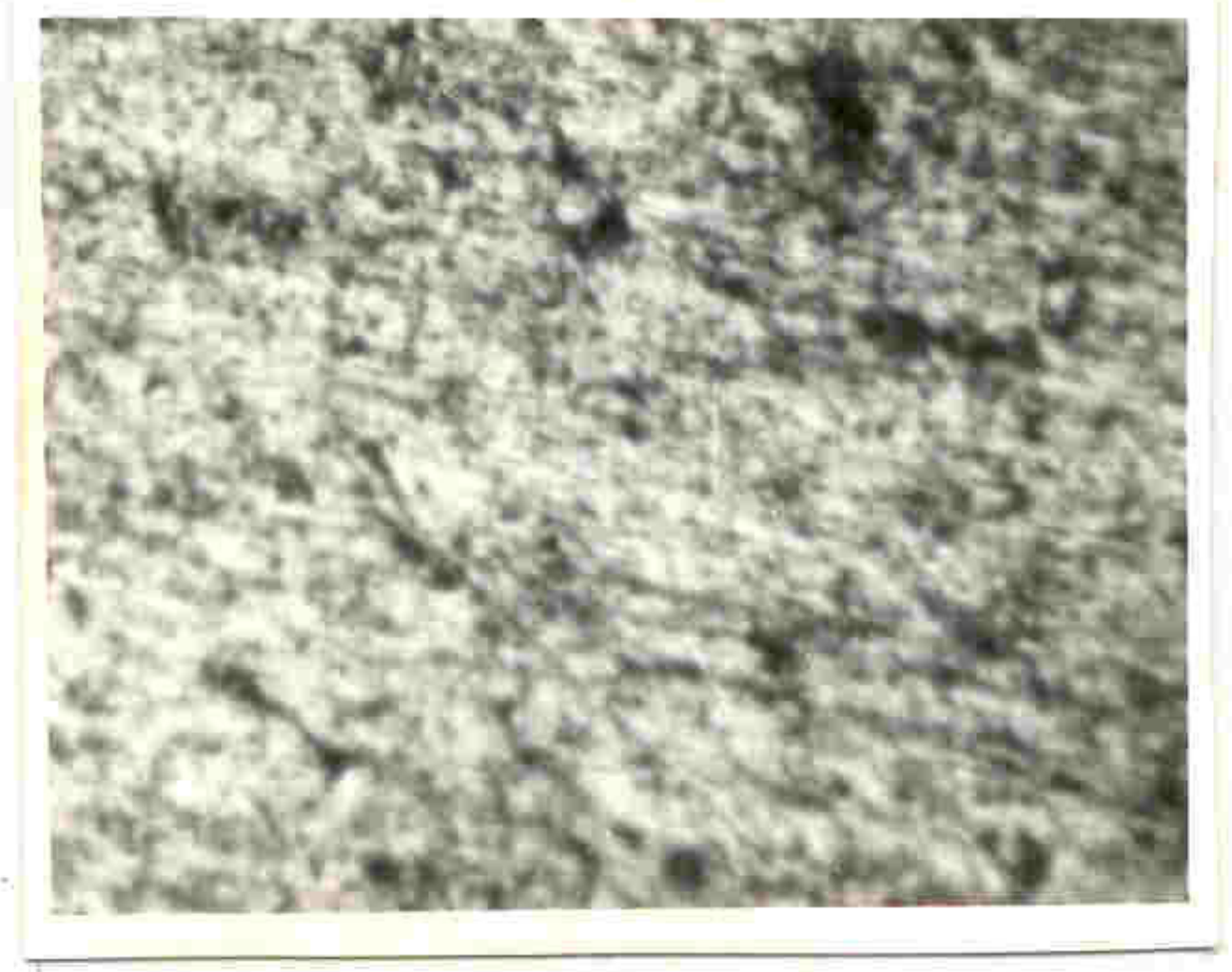

Figure 5. Microstructure of Sample Treated at $180{ }^{\circ} \mathrm{C}$. Magnifications (x100)

Figure 5 show the response of the aluminium alloy to heat treatment at the microstructural point of view due to formation of $\mathrm{Mg}_{2} \mathrm{Si}$ intermetallic compound. The revealed structure in Figure 5 shows a well dispersed precipitate of the $\mathrm{Mg}_{2} \mathrm{Si}$ intermetallic compound (black) in Al- Matrix (white) compared to what was observed in Figure 4. This was responsible for the improved properties for the sample compared to the sample that was treated at $160{ }^{\circ} \mathrm{C}$.

\section{CONCLUSION}

It has been observed that ageing temperature influence the precipitation of $\mathrm{Mg}_{2} \mathrm{Si}$ intermetallic compound in $\mathrm{Al}-\mathrm{Mg}-\mathrm{Si}$ alloy and hence, its microstructures as shown in Figures 4 and 5. Since the structure of a material determines its properties, which invariably determine its application. Proper attention must be given to the ageing temperature when the strength of the material is to be improved. Ageing at $180^{\circ} \mathrm{C}$ for $8 \mathrm{hrs}$ enhance uniform dispersal of the $\mathrm{Mg}_{2} \mathrm{Si}$ intermetallic compound precipitate in solid solution strengthening techniques and, hence, better mechanical properties than what obtains at $160^{\circ} \mathrm{C}$. 
The results have shown that percentage elongation and impact energy decreases with increase in ageing temperature while ultimate tensile strength, yield strength and hardness increases with increase in ageing temperature.

\section{REFERENCES}

[1] Helby, M. (1993) Aluminium Extrusion. A Flexible Approach Construction Mater World, Vol. 1: 101-102.

[2] Kemal, D.,Vanja, A.,and Dragan,R. (2005) The Influence of Extrusion Process and Heat Treatment on the Properties of some AA6000 Extruded Profiles, Material Technology (MTAEC9), 39(4): 101-106.

[3] Buha,J.,Lumley,R.N., and Crosky,A.G. (2006) Microstructural Development and Mechanical Properties of Interrupted Aged Al-Mg-Si-Cu Alloy,Metallurgical and Materials Transactions A, Vol.37A: 3119.

[4] Conserva,M.D., Trippodo,R. (1992) Aluminium and its Application, Gratia7-Baguolo MellaBrescia Italy,First ed.: 47-69,93-116,125-151.

[5] Raymond,H.A. (1991) Engineering Metallurgy Part1, Applied Physical Metallurgy, Clays Ltd. St. Ives Plc,England.Fifth ed.: 97-99.

[6] Donald,A.R. (1994) The Science and Engineering of Materials, PWS Engineering Boston, Massachusetts Publisher: 302-309.

[7] Maruyama, N., Uemori, R., Hashimoto, N., Saga, M., Kikuchi, M. (1997) Scripta Mater. 36 (1): 89-93.

[8] Thomas,C.H. (1990) Mechanical Behaviour of Materials, Mc Graw-Hill Publishing Co. Second ed.: 309-317.

[9] William,F.S. (1990) Principles of Materials Science and Engineering, Mc Graw-Hill Publishing Co. Second ed.: 290-292. 